\title{
Studies on Wear Properties of Polystyrene in the Presence of Fibrillated Network of Polytetrafluoroethylene
}

\author{
Sumanda Bandyopadhyay, ${ }^{1}$ Rajgopal Iyer, ${ }^{1}$ Rajdeep Majumder, ${ }^{2}$ \\ B. Satapathy, ${ }^{2}$ and Anup K. Ghosh ${ }^{2}$ \\ ${ }^{1}$ Sabic Research \& Technology (P) Ltd., Plot No. 81 to 85, Chikkadunnasandra Village, Anekal Taluk, \\ Off Sarjapur-Attibele State Highway, Bangalore 562125, India \\ ${ }^{2}$ Center for Polymer Science \& Engineering, Indian Institute of Technology, Delhi, Hauz Khas, New Delhi, India \\ Correspondence should be addressed to Rajgopal Iyer; rajgopal.iyer@sabic-ip.com
}

Received 18 April 2013; Accepted 26 May 2013

Academic Editors: G. Gentile, A. Hashidzume, D. Pavel, and B. G. Soares

Copyright (C) 2013 Sumanda Bandyopadhyay et al. This is an open access article distributed under the Creative Commons Attribution License, which permits unrestricted use, distribution, and reproduction in any medium, provided the original work is properly cited.

\begin{abstract}
Polystyrene (PS) is an important commodity plastic; however, it is not known as a suitable material for tribological applications. It has a relatively high friction coefficient in contact with metallic surfaces and high abrasion loss factor. Polytetrafluoroethylene (PTFE) is a known friction modifier, has a low friction coefficient, and is extensively used to reduce the friction coefficient and wear rate (with engineering plastics to improve tribological properties). It is known for fluoroelastomers and engineering plastics that fine particles of PTFE have the greatest effect on improving the specified properties. Here, oriented, fibrillated network morphology of PTFE in PS matrix was prepared. The wear studies show a large reduction in both the friction coefficient (45\% reduction) and the wear rate ( $2 \%$ incorporation of PTFE leads to a $49 \%$ reduction). But the friction coefficients do not show any significant change on increasing PTFE. A similar observation was made for the wear rate. Scanning electron microscope (SEM) images of the worn surfaces show a crack tip bridging mechanism, and it was observed that with the increase in PTFE content, the extent of crack tip bridging increases. This extensive improvement may be attributed to the unique morphology of the blend system.
\end{abstract}

\section{Introduction}

Blending of polymers is mixing of two or more polymers or copolymers to modify the material property to suit any desired end application in a fast and inexpensive route. There are mainly three different routes of making polymer blends: solution casting, emulsion mixing, and melt mixing. Of the three routes, solution casting is practiced nearly exclusively in laboratory scale processes, due to the difficulties in scale-ups. Melt mixing is the most widely used method of polymer blending and can be done in different equipment, namely, static batch mixing equipment, static kneading equipment, and mixing in extruders. Polymer blends can be homogeneous or heterogeneous mixtures depending on the miscibility and compatibility of the components.

The properties of polymer blends depend not only on their individual properties or amount but also, in the case of heterogeneous systems on the nature of the interphase, which in turn is dependent on the morphology of the blend system. Morphology development in blends is a process of evolution of spatial geometry or arrangement of the phases of the constituent polymers. Thus, it would be very desirable if the morphology could be controlled by the blending operation, since that would impart a higher degree of control over the final property of the blend. There is significant research being conducted on polymer tribology; nevertheless, the basic understanding of polymer tribology is still insufficient, such as the relationship between hardness and wear properties [1].

Blending of polymers is a complicated mixing process involving nonisothermal, non-Newtonian, creeping, or extensional flow. Various morphologies can be realized via processing of incompatible polymer blends. Three basic morphologies that are commonly encountered are dispersed, stratified, and cocontinuous phases in the blend. Dispersed 
morphology of polymer blends could further be subdivided into droplet and rod or fibril type in a matrix [2]. The morphology of a polymer blend develops as a result of stress level, interfacial tension mixing history, composition, and melt rheology of the components [3-5].

Han theoretically described the detailed mechanism of fibril formation of the dispersed phase in the case of simple shear flow depending on viscosity ratio, flow field, and temperature [6]. Later, Lee and Han extended the model to twin screw extruders [7]. But this model is a generalized model and not specific to fibrillation. The extent of fibril formation (dimensions of the formed fibrils) is controlled by a dimensionless number called capillary number. The capillary number $(\mathrm{Ca})$ is the ratio between the viscous force and the interfacial force, where the former tends to break the droplet and the latter tends to keep it spherical. It is defined as

$$
d=\frac{2 \gamma \mathrm{Ca}}{\eta},
$$

where $d=$ diameter of the fibril, $\sigma=$ interfacial tension between the matrix and dispersed phase, $\mathrm{Ca}=$ capillary number, $\eta=$ viscosity of the matrix, and $\gamma=$ shear rate [8]. Fibrillation of PTFE has received much attention in the literature, mostly in the solid state, in neat PTFE samples, or in blends with PTFE as a major component or PTFE in paste extrudate. PTFE has a melting point $>300^{\circ} \mathrm{C}$ and a glass transition temperature ( $\sigma$ transition) of $\sim 116^{\circ} \mathrm{C}$. The present study has been done at around $200^{\circ} \mathrm{C}$, implying that the deformation of the polymer would take place in its rubbery state rather than in the melt state, and the present theories hold good.

In general, the improvement in the mechanical properties of polystyrene (PS) by the addition of filler is low, and hence, addition of mineral filler in PS has received very little attention [9]. Further, PS has not found much structural application due to the high brittleness of the polymer, and blending of PTFE with PS has not received much attention. However, the improvement of toughness and tensile strength properties of PS by the incorporation of rubber to make high impact polystyrene (HIPS) is well known. The use of styrenics has been divided into three categories:

(1) for transparent molding, neat PS and copolymers of styrene or substituted styrene and acrylonitrile, acrylates, and so forth,

(2) for higher impact properties, HIPS or acrylonitrile butadiene styrene (ABS),

(3) in packaging industry, expanded PS foam has been used.

PS has an excellent dielectric property (dielectric constant and power factor) which is nearly independent of frequency (between $60 \mathrm{~Hz}$ and $106 \mathrm{~Hz}$ ) and therefore has been used extensively in electrical fittings. PTFE has found application due to its excellent chemical resistance, thermal stability, and flame retardant property. Due to its low coefficient of friction, excellent insulation properties across high temperature and frequency range and self-lubricating property, it
TABLE 1: Batch details of TSAN-GPPS blends.

\begin{tabular}{lcc}
\hline Batch name & GPPS (\%) & TSAN (\%) \\
\hline T2PS & 98 & 2 \\
T4PS & 96 & 4 \\
T10PS & 90 & 10 \\
T20PS & 80 & 20 \\
\hline
\end{tabular}

has been extensively used in seals, gaskets, coating on metals (where friction is encountered), and electrical insulation [10]. Further, because of its lubricating properties, it has been extensively used, as a minor component, as an internal lubricant with high performance plastics, and as an additive to lower the coefficient of friction and improve wear property. However, due to its high creep under low stresses, PTFE has not found much application outside the fields mentioned previously. In this regard, PEEK-PTFE blends are of extensive use, due to high improvement in wear properties, where PTFE lowers the friction coefficient and increases the wear resistance [11, 12]. The coefficient of friction of PTFE on PTFE is only 0.037 as compared to that of polycaprolactam on polycaprolactam, which is 0.62 , also known to be selflubricating [13].

The main drawback of blending PTFE in other polymers is that it has poor dispersion in thermoplastics that have no fluorine atom as part of their repeat units. To overcome this problem, in the present study, polytetrafluoroethylenestyrene-acrylonitrile copolymer (TSAN) has been used. TSAN is a $50: 50$ weight percent blend of PTFE and styrene acrylonitrile (SAN), where PTFE particles are at least partially encapsulated by SAN, and the SAN component brings in the compatibility with other thermoplastic polymers.

\section{Materials and Methods}

The polymers used in the experiment were General Purpose Polystyrene (GPPS-supreme SC203EL) MFI 8 (g/10 min) and Teflon (PTFE)-Styrene-Acrylonitrile (TSAN) (GE Plastics C004449). The weight average molecular weight of the SAN was $\sim 4 \times 10^{5}$ with $26.85 \%$ acrylonitrile content. The melting point of virgin polytetrafluoroethylene (PTFE) in TSAN was $337^{\circ} \mathrm{C}$ (found from modulated differential scanning calorimetry (MDSC)).

The details of the blends are given in Tables 1 and 2. Due to the higher loading of TSAN in the T10PS and T20PS blends ( $5 \%$ and $10 \%$, resp.), blend of $5 \%$ and $10 \%$ SAN were prepared to measure the effect of SAN on the mechanical properties of neat GPPS. A W\&P 25 twin screw extruder was used with total 23 elements consisting of kneading and conveying blocks, for extruding the blends at $300 \mathrm{rpm}$.

After compounding, the strands were pelletized and dried at $85^{\circ} \mathrm{C}$ for 4 hours. The injection molding of the specimen was done using an L\&T injection molding machine (L\&T DEMAG ASWA 100/420-310). The temperature profile for the compounding and the molding process is mentioned in Table 3.

SEM studies were carried out on an FEI Quanta 400 microscope. The cryogenically fractured surface of injection 
TABLE 2: Batch details of GPPS-SAN blends.

\begin{tabular}{lcc}
\hline Batch name & GPPS (\%) & SAN (\%) \\
\hline PSAN1 & 95 & 5 \\
PSAN2 & 90 & 10 \\
\hline
\end{tabular}

molded specimen, coated with a very thin layer of gold (to mitigate charging effects), was imaged in the secondary electron detector mode. The MDSC studies were done using a TA Instruments DSC Q1000 V9.9 Build 303. The samples were heated rapidly from room temperature to $300^{\circ} \mathrm{C}$ and kept isothermally for 5 minutes to stabilize the temperature before starting the sinusoidal (modulated) heating. The sample was subjected to an amplitude modulation of $0.5^{\circ} \mathrm{C}$ for a period of 40 seconds while scanning at a linear rate of $5^{\circ} \mathrm{C} / \mathrm{min}$ from $300^{\circ} \mathrm{C}$ to $360^{\circ} \mathrm{C}$. A nitrogen purge was maintained to obtain a stable baseline and thermal conductivity. Tensile properties were studied on a Zwick/Roell Z010 UTM. The tests were carried out according to ISO 527, with the samples conditioned at $23^{\circ} \mathrm{C} \pm 0.5^{\circ} \mathrm{C}$ at a relative humidity of 50 $\pm 5 \%$. Moduli were determined at a crosshead speed of $1 \mathrm{~mm} / \mathrm{min}$ to $0.25 \%$ strain, and the rest of the test was carried out at a crosshead speed of $5 \mathrm{~mm} / \mathrm{min}$. The notched and unnotched Izod impact energies were found out according to ISO 180 with a CEAST Resil Impactor. For GPPS and TSANGPPS blends, a 2 J hammer was used. Dynamic mechanical thermal analysis was done to determine the change in elastic modulus and loss modulus with temperature. The test was done in a three-point bending mode. The test samples were $48 \times 10 \times 4 \mathrm{~mm}$ in dimension. The distance of the supports was $40 \mathrm{~mm}$. The tests were carried out over a temperature range of $-20^{\circ} \mathrm{C}$ to $95^{\circ} \mathrm{C}$ for GPPS and its blends at a rate of $2^{\circ} \mathrm{C} / \mathrm{min}$ and a frequency of $1 \mathrm{~Hz}$. Liquid nitrogen was used to maintain the low temperatures, as required, and was also used to precisely control temperatures during heating. The strains at the linear viscoelastic region (LVR) of each sample were determined before the temperature ramp tests. The wear tests were carried out in CSM Instruments: High Temperature Tribometer Pin on Disk wear instrument. The coefficient of static friction and the volumetric wear were studied. The wear studies were carried out with an EN 31 chrome steel ball of $6 \mathrm{~mm}$ diameter as the abrading agent. The studies were carried out at three different loads and two different speeds. The loads as well as the speeds were kept low to moderate values to keep the stresses values low. The three loads used were $5 \mathrm{~N}, 7 \mathrm{~N}$, and $15 \mathrm{~N}$, respectively. The test speeds were $15 \mathrm{~cm} \mathrm{~s}^{-1}$ and $25 \mathrm{~cm} \mathrm{~s}^{-1}$. Figure 1 shows an image of the test setup.

\section{Results and Discussion}

The morphological characterization was done using a scanning electron microscope operated at $20-30 \mathrm{kV}$. The SEM images of PS-TSAN blends are shown in Figure 2. In case of $10 \%$ TSAN filled composite (T10PS, Figure 2(b)), a new feature, that of fibrils, which is completely absent in $4 \%$ TSAN loaded samples (T4PS, Figure 2(a)), is observed. The diameter of the fibrils ranged from $\sim 90 \mathrm{~nm}$ to $\sim 830 \mathrm{~nm}$,

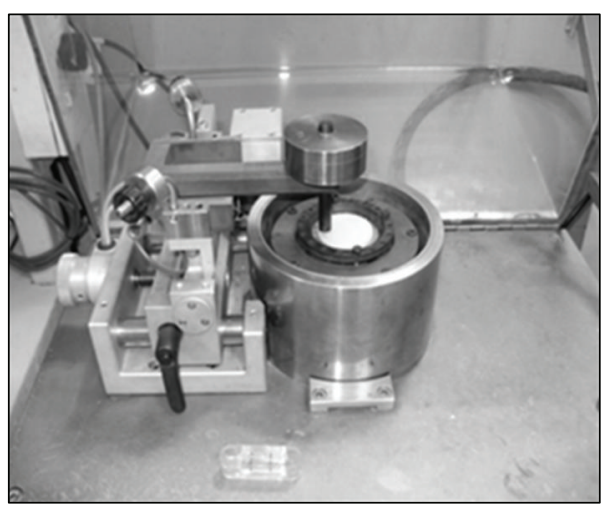

FIGURE 1: Wear test setup.

with most fibrils in the diameter range of $\sim 125 \mathrm{~nm}-\sim 170 \mathrm{~nm}$. Fibrils with diameter above $700 \mathrm{~nm}$ were not that abundant.

It is difficult to get an idea about the length of the fibrils, because at the fracture surface there is a chance of fibril breakage, and also in the case of networks, it is difficult to ascertain the length of the fibrils. It can be seen that there are individual fibrils, with lengths varying between $\sim 5 \mu \mathrm{m}$ and $~$ $25 \mu \mathrm{m}$. In the case of $20 \%$ TSAN (T20PS, Figure 2(c)) loaded samples, the bulk of fibrils with larger diameter increases and the network structure is more prominent. Overall, the fibril diameters were found to vary from approximately $100 \mathrm{~nm}$ to $400 \mathrm{~nm}$ with most fibrils having diameter between $100 \mathrm{~nm}$ and $300 \mathrm{~nm}$. For samples with higher loading of TSAN, fibrils with diameter higher than $700 \mathrm{~nm}$ and up to $2.5 \mu \mathrm{m}$ were also observed. MDSC study was used to quantify the fibrils in the composites by monitoring the change in the melting point. It has been shown in the past that for extended chain flexible polymer crystals, the crystals superheat when the chains are retrained and/or extended [14]. Several authors have reported that superheating is higher $\left(\operatorname{Tm} \approx \operatorname{Tm} 0+10^{\circ} \mathrm{C}\right.$, where the equilibrium melting temperature $\operatorname{Tm} 0$ has been reported in the range of $332-336^{\circ} \mathrm{C}$ ) [15-18]. Pucciariello et al. applied MDSC in the quasi-isothermal mode to investigate melting and crystallization of PTFE $[19,20]$. They confirmed the strong differences in the melting temperature of meltcrystallized and as-polymerized PTFE. They concluded that the double melting pattern for as-polymerized PTFE is well resolved. This was further used by Agarwal et al. [21] to quantify the extent of fibrillation. All MDSC signals are derived from three measured parameters: time, modulated temperature (stimulus), and modulated heat flow (response). The amount of PTFE is low in the composites, and hence the difference in the melting points of PTFE crystals before and after the fibrillation is rather small. Therefore, it is not possible to get the extent of fibrillation in a straightforward manner. The heat flow data were plotted, and a process of deconvolution of the peaks was done. The ratio of fibrillated and unfibrillated parts of PTFE can be found out from the relative areas under the curves. The heat flow data between $320^{\circ} \mathrm{C}$ and $350^{\circ} \mathrm{C}$ was resolved at an increment of $1.0^{\circ} \mathrm{C}$. From the deconvoluted plots, the ratio of the fibrils was calculated from the area under the curves at the different temperatures. 
TABLE 3: Temperature profile of the TSE and injection molding machine.

\begin{tabular}{lccccc}
\hline & & & Zone & & \\
& 1 & 2 & 3 & 2 & Nozzle \\
\hline TSE Temp. $\left({ }^{\circ} \mathrm{C}\right)$ & 180 & 200 & 210 & 220 & 230 \\
\hline & Nozzle & MH3 & MH2 & MH3 & Mold \\
\hline Injection molding machine Temp. $\left({ }^{\circ} \mathrm{C}\right)$ & 230 & 200 & 220 & 200 & 70 \\
\hline
\end{tabular}

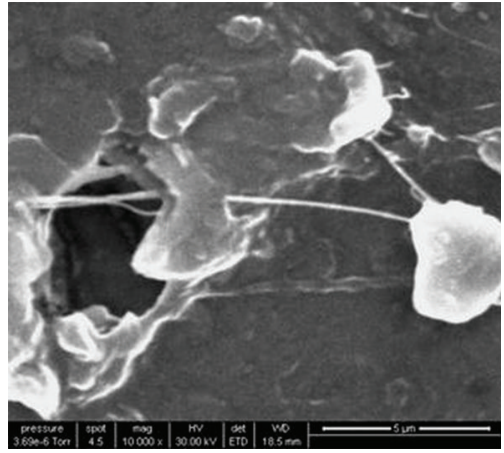

(a)

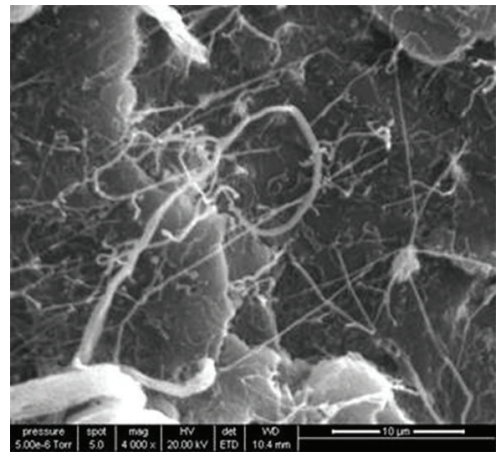

(b)

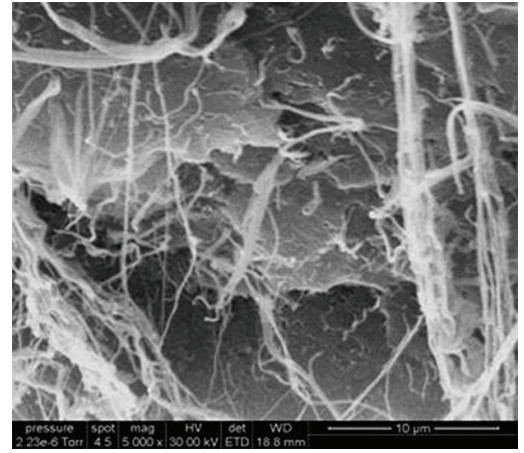

(c)

FIGURE 2: SEM images showing fibrillation for (a) T4PS, (b) T10PS, and (c) T20PS.

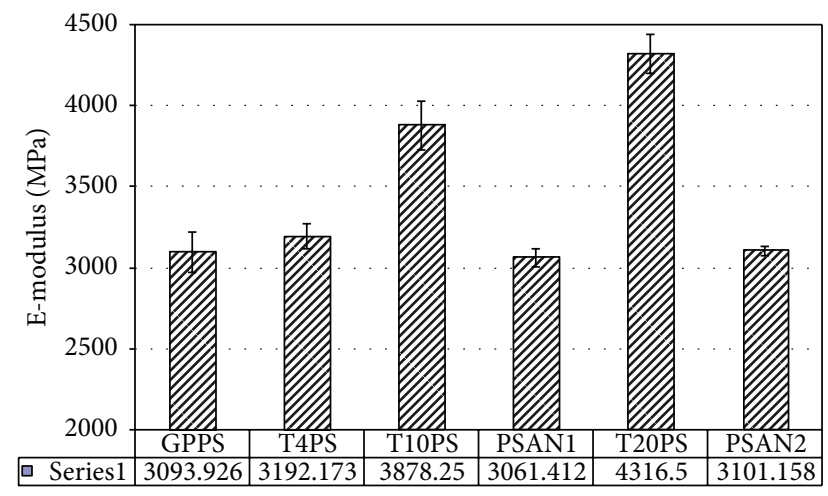

FIgURE 3: Comparison of E-modulus values.

SEM images earlier showed a higher amount of fibrils compared to the MDSC study, a possible explanation for low values from MDSC. It is possible that, for fibrils with bigger dimensions, the crystals are similar to that in the nodes, for example, the virgin polymer. From the SEM images, at higher loading of the samples, a large amount of fibrils with diameter over $700 \mathrm{~nm}$ can be observed. In the MDSC study, they show up as nodes rather than fibrils. The node-to-fibril ratio is shown in Table 4.

The tensile modulus result of PS and PS-TSAN blends is shown in Figure 3. It is seen from the experimental data that PTFE is acting as a reinforcing agent at very low strains. From the control samples, it is clear that the improvement in modulus is only due to the presence of fibrillated PTFE. But there is no significant change in the tensile strength prompting an assumption of phase separation at relatively higher strain, which is expected from the lubricating nature

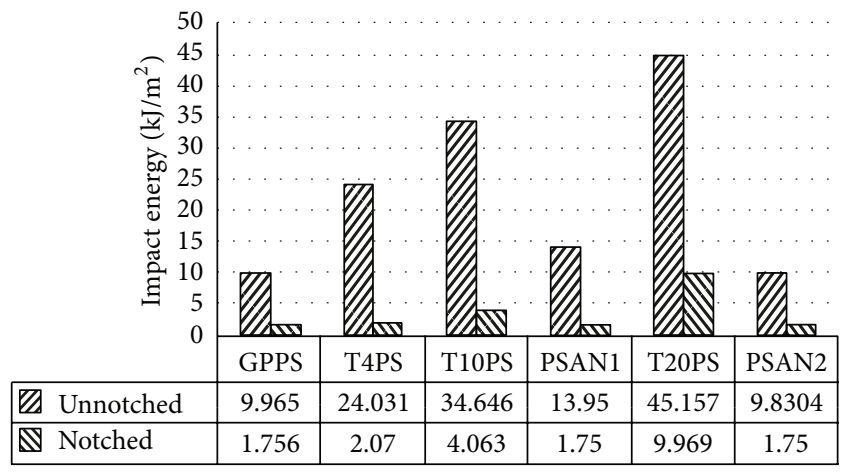

FIGURE 4: Comparison of impact energy values.

of PTFE. Figure 4 compares notched and unnotched values for the impact energies. The unnotched values are higher than the notched values because the fibrils are damaged during the notching process and hence a reduced impact energy.

Dynamic mechanical properties of GPPS and TSAN blend samples were studied. The strains at the linear viscoelastic region (LVR) of each sample were found to be between $0.01 \%$ and $0.03 \%$. The maxima of the $G^{\prime \prime}$ curves were used as the measure of Tg according to ASTM D 4065-06. The DMA results showed an interesting trend. After $19^{\circ} \mathrm{C}$, when a 1st order glass-to-glass transition starts in PTFE, the storage modulus of composites with higher PTFE loading tends to come together, and above $30^{\circ} \mathrm{C}$, and when the second and smaller 1st order transition takes place, the values of the storage modulus are virtually the same. Here, $E^{\prime}$ values are listed for two different temperatures- $20^{\circ} \mathrm{C}$ and $\sim 32^{\circ} \mathrm{C}$. The $E^{\prime \prime}$ values are listed for the peak value. The results are tabulated in Table 5. 


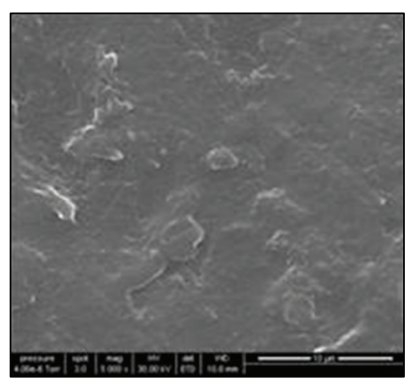

(a)

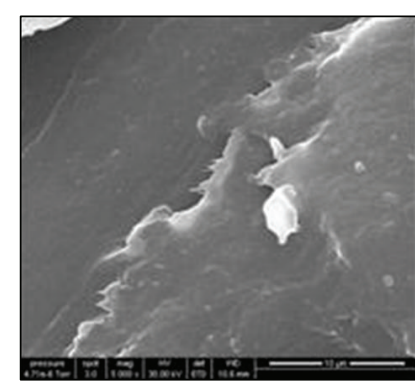

(b)

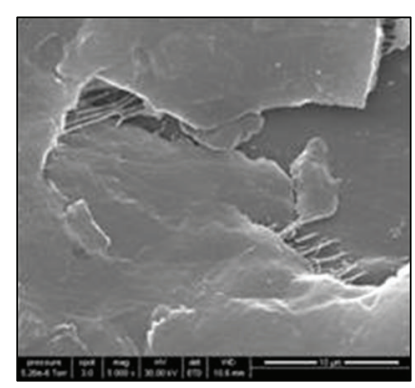

(c)

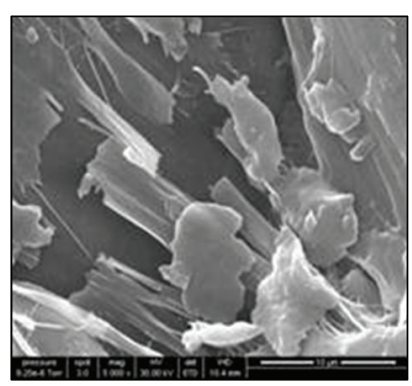

(d)

FIGURE 5: SEM images of the wear surfaces for (a) GPPS, (b) T4PS, (c) T10PS, and (d) T20PS. Scale: $10 \mu \mathrm{m}$.

TABle 4: Node to fibril ratio.

\begin{tabular}{lc}
\hline Sample & Node $:$ fibril ratio \\
\hline T4PS & $1: 4.2$ \\
T10PS & $1: 2.3$ \\
T20PS & $1: 0.7$ \\
\hline
\end{tabular}

TABLE 5: Dynamic mechanical properties of GPPS and TSAN blend samples.

\begin{tabular}{lcccc}
\hline & \multicolumn{2}{c}{$E^{\prime}(\mathrm{GPa})$} & \multicolumn{2}{c}{$E^{\prime \prime} \max$} \\
& $20^{\circ} \mathrm{C}$ & $32^{\circ} \mathrm{C}$ & Temp. $\left({ }^{\circ} \mathrm{C}\right)$ & $\mathrm{MPa}$ \\
\hline GPPS & 2.01 & 1.99 & 85 & 302.79 \\
T4PS & 2.35 & 2.28 & 83 & 314.91 \\
T10PS & 3.19 & 3.03 & 85 & 472.57 \\
T20PS & 3.32 & 3.04 & 82 & 542.3 \\
\hline
\end{tabular}

TABLE 6: Coefficient of friction of PS and PS-based composites.

\begin{tabular}{lc}
\hline Sample & Wear rate $(\mathrm{cc} / 100 \mathrm{~m})\left(10^{-4}\right)$ \\
\hline GPPS & 88.1 \\
T4PS & 43.4 \\
T10PS & 5.6 \\
T20PS & 7.3 \\
\hline
\end{tabular}

TABLE 7: Volumetric wear of PS and PS-based composites.

\begin{tabular}{lc}
\hline Sample & Coefficient of friction \\
\hline GPPS & 0.28 \\
T4PS & 0.13 \\
T10PS & 0.15 \\
T20PS & 0.10 \\
\hline
\end{tabular}

The $E^{\prime}$ and $E^{\prime \prime}$ versus temperature plots for all the samples were studied in detail. For brevity, these plots have not been included. As observed in the $E^{\prime \prime}$ versus temperature plots, the 1st order transition of PTFE at $\sim 19^{\circ} \mathrm{C}$ can be clearly seen for higher loading of PTFE. It can be seen that plot for GPPS and T4PS as well as T10PS and T20PS is identical up to $60^{\circ} \mathrm{C}$. But the slope is higher in the second set, that is, T10PS and T20PS. In the case of $E^{\prime}$ versus temperature plot too, a similar trend is seen. As far as the rate of change of modulus is concerned, the presence of PFTE makes the modulus more sensitive to temperature change. It may be due to the enhanced molecular motion of PTFE or due to the increasing phase separation of PFTE and PS phases, whereby the stress transfer is impeded and the response from PTFE introduces the higher rate of change of modulus. The coefficient of friction showed a drastic reduction on blending with PTFE. The coefficient of friction for neat GPPS is $\sim 0.33$. Upon mixing with $2 \%$ PTFE, the friction coefficient reduces to 0.17 . With further increase in PTFE loading, there is no significant decrease in the friction coefficient. The values for $15 \mathrm{~N}$ load and $25 \mathrm{~cm} \mathrm{~s}^{-1}$ are shown in Table 6.

There is also a drastic reduction in the volumetric wear in case of PTFE loaded composites. The volumetric wear of PS and PS-TSAN composites at $15 \mathrm{~N}$ load and $25 \mathrm{~cm} \mathrm{~s}^{-1}$ speed is shown in the Table 7 . The worn-out surfaces were studied by scanning electron microscopy to get an understanding of the effect of PTFE on the wear. From the SEM images (Figure 5) of the wear surfaces, it seems that for wear, PTFE at low to moderate loading decreases the wear by bridging the crack tips of resulting microlevel fractures at the surface. The efficiency of this bridging increases with increasing PTFE content. In case of higher PTFE loadings, it seems that PTFE may be acting by forming a surface layer.

\section{Conclusion}

From the present study, it can be concluded that, around the processing temperature of $\sim 200^{\circ} \mathrm{C}$, the ease of fibrillation and the fibril dimensions are not very sensitive to the viscosity of the matrix. The final fibril dimensions are more sensitive to the amount of PTFE in the composite. From the tensile and flexural properties, it can be concluded that PTFE acts as a reinforcing agent at very low strains. At relatively higher strain, due to the very poor phase adhesion of PTFE, phase separation takes place, and thereby, stress transfer is hampered, further leading to the observed lack of any significant change in the tensile and flexural strength. This conclusion is also supported by the DMTA studies, where the values of the T10PS and T20PS samples showed nearly equal values of storage modulus after $30^{\circ} \mathrm{C}$. From the DMTA studies, the chain movement of the PTFE is also evident from the pattern of the $E^{\prime}$ and $E^{\prime \prime}$ plots of the composites with higher loading of PTFE compared to neat PS. Scanning 
electron microscopy studies showed extensive fibrillation. The quantification of fibrils by MDSC studies yielded results that were not supportive of the SEM observation. From that, it is concluded that for fibrils with bigger dimensions, the melting behaviour is similar to the virgin polymer. From the coefficient of thermal expansion, the interesting aspect of the distribution of crystallites in the fibrils was observed. The presence of the characteristic peak of PTFE $\sim 20^{\circ} \mathrm{C}$ only in the flow direction suggests that the " $\mathrm{c}$ " direction of the PTFE crystals is aligned in the fibril axis direction. It is also expected that fibrils will be aligned in the flow direction during injection molding. Wear study concludes the significant improvement in the wear performance of PS matrix in presence of TSAN. Further study is currently ongoing to determine the wear mechanism and to validate such a crack-tip bridging phenomenon in other polymers.

\section{Acknowledgments}

The authors would like to thank the support and cooperation from the Centre for Polymer Science and Engineering, IIT Delhi and Innovative Plastics Group at GE India Technology Centre, Bangalore.

\section{References}

[1] W. Brostow, W. Clwnkaew, and K. P. Menard, "Connection between dynamic mechanical properties and sliding wear resistance of polymers," Materials Research Innovations, vol. 10, no. 4, p. 109, 2006.

[2] H. E. H. Meijer, P. J. Lemstra, and P. H. M. Elemans, "Structured polymer blends," Makromolekulare Chemie. Macromolecular Symposia, vol. 16, no. 1, pp. 113-135, 1988.

[3] J. M. Starita, "Microstructure of melt blended polymer systems," Transactions of The Society of Rheology, vol. 16, pp. 339-367, 1972.

[4] H. van Oene, "Modes of dispersion of viscoelastic fluids in flow," Journal of Colloid and Interface Science, vol. 40, no. 3, pp. 448467, 1972.

[5] A. P. Plochocki, "Melt rheology of polymer blends the morphology feedback," Polymer Engineering and Science, vol. 23, no. 11, pp. 618-626, 1983.

[6] C. D. Han, Multiphase Flow in Polymer Processing, John Wiley \& Sons, New York, NY, USA, 1981.

[7] J. K. Lee and C. D. Han, "Evolution of polymer blend morphology during compounding in a twin-screw extruder," Polymer, vol. 41, no. 5, pp. 1799-1815, 2000.

[8] H. A. Stone, "Dynamics of drop deformation and breakup in viscous fluids," Annual Review of Fluid Mechanics, vol. 26, pp. 65-102, 1994.

[9] R. Gachter and H. Muller, Plastics Additives Handbook, Stabilizers, Processing Aids, Plasticizers, Fillers, Reinforcements, Colorants for Thermoplastics, Hanser, Munich, Germany, 3rd edition.

[10] J. A. Brydson, Plastic Materials, Butterworth Heinemann, Woburn, Mass, USA, 7th edition.

[11] B. Stuart, "Tribological studies of poly(ether ether ketone) blends," Tribology International, vol. 31, no. 11, pp. 647-651, 1998.
[12] J. Bijwe, S. Sen, and A. Ghosh, "Influence of PTFE content in PEEK-PTFE blends on mechanical properties and triboperformance in various wear modes," Wear, vol. 258, no. 10, pp. 1536-1542, 2005.

[13] L. H. Lee and K. C. Ludema, Friction and Wear of Polymers, Elsevier, New York, NY, USA, 1981.

[14] B. Wunderlich, Macromolecular Physics: Crystal Structure, Morphology, Defects, vol. 1, Academic Press, New York, NY, USA, 1973.

[15] B. Wunderlich, Macromolecular Physics: Crystal Nucleation, Growth, Annealing, vol. 2, Academic Press, New York, NY, USA, 1976.

[16] B. Wunderlich, Macromolecular Physics: Crystal Melting, vol. 2, Academic Press, New York, NY, USA, 1980.

[17] D. C. Bassett and R. Davitt, "On crystallization phenomena in polytetrafluoroethylene," Polymer, vol. 15, no. 11, pp. 721-728, 1974.

[18] S. F. Lau, H. Suzuki, and B. Wunderlich, “Thermodynamic properties of polytetrafluoroethylene," Journal of Polymer Science B, vol. 22, no. 3, pp. 379-405, 1984.

[19] R. Pucciariello, V. Villani, and C. Mancusi, "On meltcrystallization of polytetrafluoroethylene and of random fluorinated copolymers of tetrafluoroethylene," Journal of Applied Polymer Science, vol. 74, no. 7, pp. 1607-1613, 1999.

[20] R. Pucciariello and V. Villani, "Melting and crystallization behavior of poly(tetrafluoroethylene) by temperature modulated calorimetry," Polymer, vol. 45, no. 6, pp. 2031-2039, 2004.

[21] N. Agarwal, S. K. Gaggar, D. Gupta et al., "Polymer compositions, method of manufacture, and articles formed therefrom," US Patent 7557154 B2. 

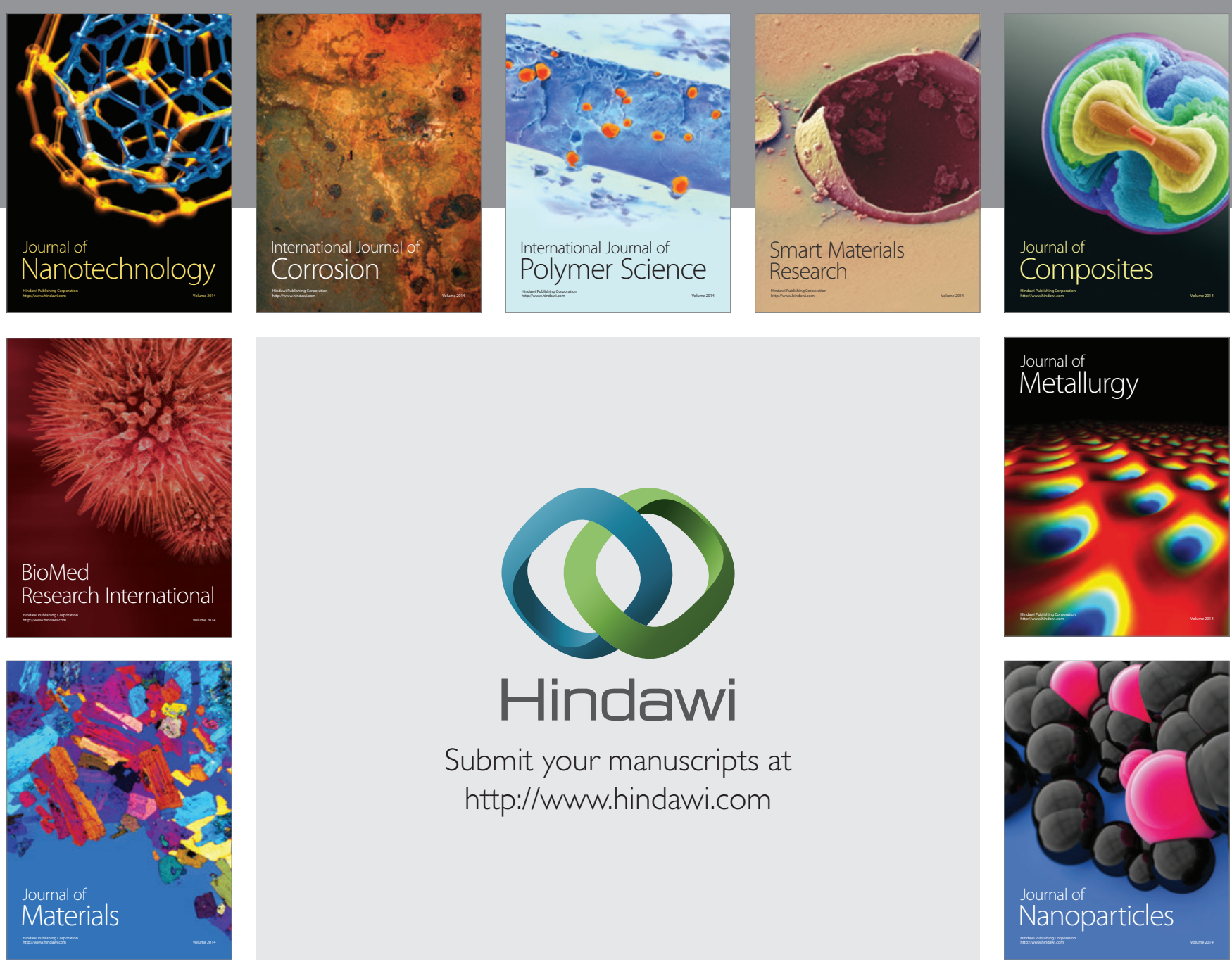

Submit your manuscripts at http://www.hindawi.com
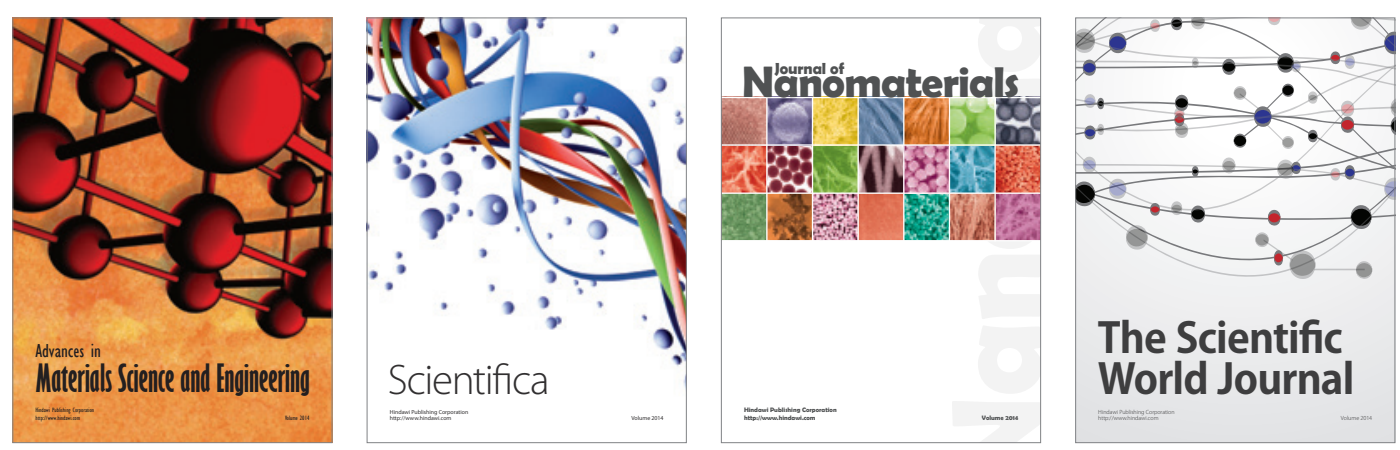

\section{The Scientific World Journal}
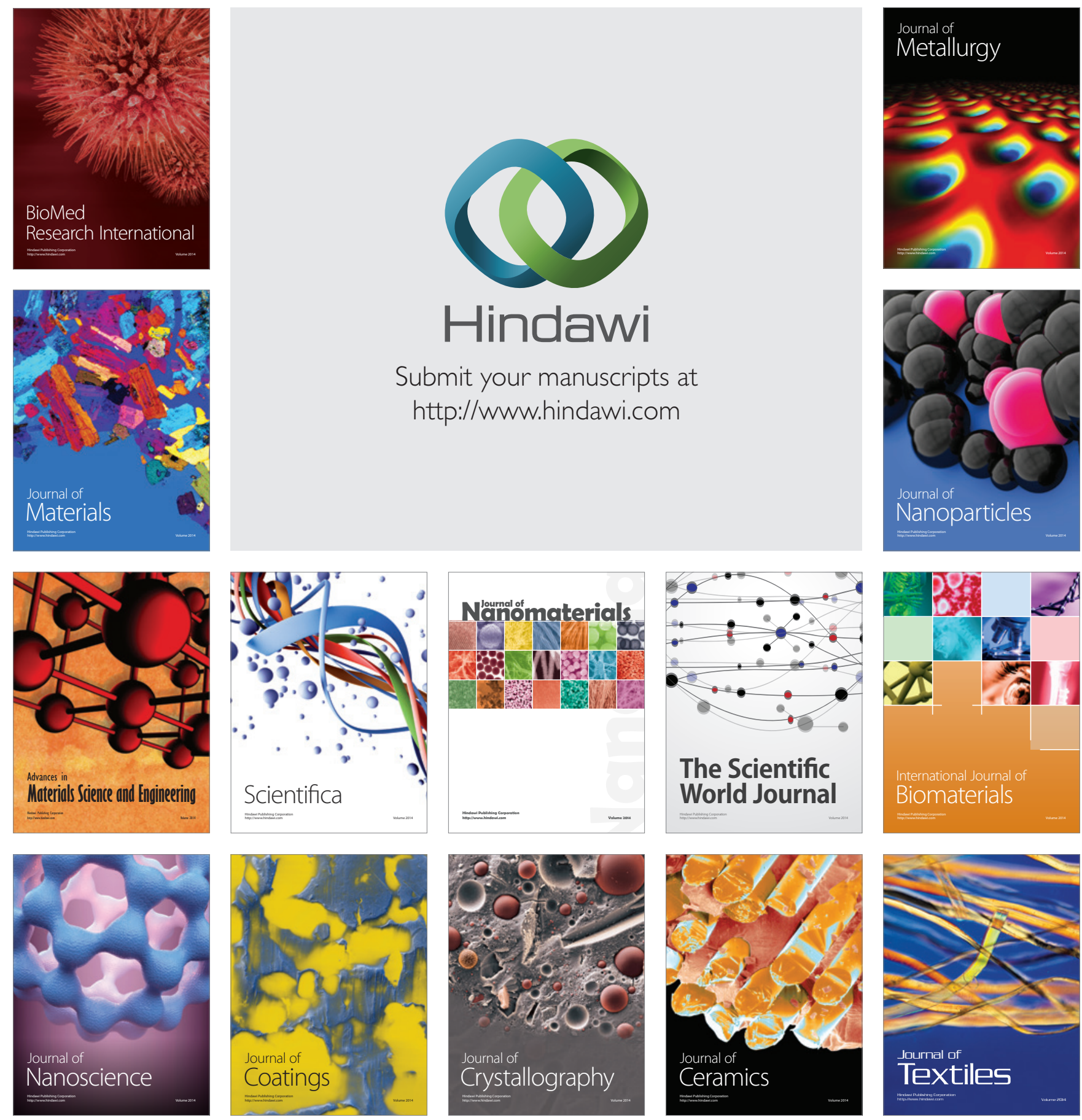